Proof of your article (\# JAP-00014-2006) from "Journal of Applied Physiology" is available for download $====$

Dear Sir or Madam:

Please refer to this URL address

http://rapidproof.cadmus.com/RapidProof/retrieval/index.jsp

Login: your e-mail address

Password:

The file at the above URL address contains the following:

- Proofreading marks

- Reprint Order form

- Copyedited page proof of your article

The site contains 1 file. You will need Adobe Acrobat ${ }^{\circledR}$ Reader to read this file. Adobe Acrobat ${ }^{\circledR}$ Reader is a free software, available for user downloading at http://www.adobe.com/products/acrobat/readstep.html.

After you print the PDF file of your paper, please read the page proof carefully and

1) clearly indicate all changes or corrections on the margin;

2) answer all queries (footnotes 1,2,3, etc.) listed on the last page of the PDF proof;

3) carefully proofread all/any tables and equations;

4) make sure that any special characters, such as Greek letters, especially $\mu$ (mu), have translated correctly;

5) If you have questions about figure quality, note your concerns on the margin of the relevant page. Please keep in mind that the final printed version will be of higher quality than the PDF proof and that the online version of the published article will appear identical.

IMPORTANT: Do NOT make online alterations to the PDF itself. Corrections within the PDF, made with the Adobe Acrobat-provided tools will remain unseen by the Journal staff. This will result in the final article NOT reflecting your intended changes. ONLY the hand-marked PDF printout guarantees that the changes will be incorporated into the final text of the article.

We encourage you to retain a copy of the proof with your corrections, should further changes and/or clarifications be required.

\title{
IMPORTANT NOTES
}

1. To guarantee the placement of your article in the next available issue of the "Journal of Applied Physiology", please return the corrected set of PDF page proof via an overnight courier service to this address WITHIN 48 HOURS:

The American Physiological Society

"Journal of Applied Physiology" PROOF

9650 Rockville Pike

Bethesda, MD 20814-3991

USA

phone: 301-634-7070

2. If you require a hard copy of your color image(s), you may request it by replying to this message. The color proof will then be provided to you at an additional fee of $\$ 75.00$ per color figure, which will be added to the publication fees for your article. You must provide the appropriate figure number(s) and your mailing address in your reply if you wish to receive the hard copy of the color proof(s).

3) The filled out Reprint Form must be returned within 24 hours to the address below: 


\section{Journal of Applied Physiology}

Copy of e-mail Notification

Cadmus Professional Communications

Cadmus Reprints

PO Box 751903

Charlotte NC 28275-1903

USA

For reprint inquiries, please contact Mary Leonard, fax: 410-770-4659, e-mail: leonardm@ @admus.com.

If you have any problems or questions, please contact me.

PLEASE ALWAYS INCLUDE YOUR ARTICLE NO. ( JAP-00014-2006 ) WITH ALL

CORRESPONDENCE.

Sincerely,

Virginia Million

Journal Editorial Supervisor

Journal of Applied Physiology

9650 Rockville Pike

Bethesda, MD 20814

Tel: 301-634-7216

Fax: 301-634-7243

E-mail: vmillion@the-aps.org 


\section{Proofreader's Marks}

\begin{tabular}{|c|c|c|c|c|c|}
\hline MARK & EXPLANATION & EXAMPLE & MARK & EXPLANATION & EXAMPLE \\
\hline$\gamma$ & $\begin{array}{l}\text { TAKE OUT CHAR- } \\
\text { ACTER INDICATED }\end{array}$ & $\delta$ Your prooфf. & & RAISE & $\neg$ lYour proof.I \\
\hline$\wedge$ & LEFT OUT, INSERT & $u$ Yor proof. & ᄃ & MOVE LEFT & {$[\quad$ Your proof. } \\
\hline \# & INSERT SPACE & \# Yourproof. & $\sqsupset$ & MOVE RIGHT & コour proof. \\
\hline 9 & $\begin{array}{l}\text { TURN INVERTED } \\
\text { LETTER }\end{array}$ & Your ploof. & & ALIGN TYPE & $\| \begin{array}{l}{\left[\begin{array}{c}\text { Three dogs. } \\
\text { Two horses. }\end{array}\right.} \\
\end{array}$ \\
\hline $\mathrm{X}$ & BROKEN LETTER & $X$ Your profof. & $=$ & STRAIGHTEN LINE & $=$ Your $\overline{\mathrm{p}^{\mathrm{roo}}}$. \\
\hline $\operatorname{egg} \#$ & EVEN SPACE & eq\#A good proof. & $\odot$ & INSERT PERIOD & $\odot$ Your proof \\
\hline ○ & $\begin{array}{l}\text { CLOSE UP: } \\
\text { NO SPACE }\end{array}$ & Your prôff. & \% & INSERT COMMA & Y) Your proof $\wedge$ \\
\hline tro & TRANSPOSE & tr A proofgood & :/ & INSERT COLON & $\because$ Your proöf $\wedge$ \\
\hline wf & WRONG FONT & wf Your prodf. & & INSERT SEMICOLON & i) Your proof $\wedge$ \\
\hline lc & LOWER CASE & ec Yourfroof. & $V$ & $\begin{array}{l}\text { INSERT } \\
\text { APOSTROPHE }\end{array}$ & $\vee$ Your mans proof. \\
\hline$\equiv$ & CAPITALS & Your proof. & ツய & $\begin{array}{l}\text { INSERT QUOTATION } \\
\text { MARKS }\end{array}$ & $\forall \bowtie$ Marked it proof $\wedge$ \\
\hline$\overline{i t a l}$ & ITALIC & $\begin{array}{l}\text { Your proof. } \\
\text { ital Your proof. }\end{array}$ & $=1$ & INSERT HYPHEN & $=$ A proofmark. \\
\hline horr & $\begin{array}{l}\text { ROMAN, } \\
\text { NON ITALIC } \\
\end{array}$ & nomYour roof. & ! & $\begin{array}{l}\text { INSERT EXCLAMATION } \\
\text { MARK }\end{array}$ & $!$ Prove it $\wedge$ \\
\hline$\tilde{\log }$ & BOLD FACE & Ye Yeus proof. & $?$ & $\begin{array}{l}\text { INSERT QUESTION } \\
\text { MARK }\end{array}$ & $?$ Is it right $\wedge$ \\
\hline & & & ? & QUERY FOR AUTHOR & (2) Your proof read by \\
\hline$\cdots \cdots$ & $\begin{array}{l}\text { LET IT } \\
\text { STAND }\end{array}$ & Fout proof. & & 4 & $\wedge$ \\
\hline stet & & stet Hour proof. & ᄃ) & INSERT BRACKETS & {$[/]$ The Smith girl } \\
\hline out sc. & $\begin{array}{l}\text { DELETE, } \\
\text { SEE COPY }\end{array}$ & $\begin{array}{l}\text { out } \\
\text { sc. She Our proof. }\end{array}$ & $c / 3$ & INSERT PARENTHESES & $c / \supset$ Your proof $1 \wedge$ \\
\hline $\begin{array}{l}\text { spell } \\
\text { out }\end{array}$ & SPELL OUT & $\begin{array}{l}\text { spell Queen Eliz. } \\
\text { out }\end{array}$ & $1 / m$ & $\begin{array}{l}\text { INSERT 1-EM } \\
\text { DASH }\end{array}$ & $1 / m$ Your proof. \\
\hline $\mathbb{R}$ & $\begin{array}{l}\text { START } \\
\text { PARAGRAPH } \\
\end{array}$ & $\mathbb{F}$ read. $[$ Your & $\square$ & INDENT 1 EM & 口Your proof \\
\hline no $\pi$ & $\begin{array}{l}\text { NO PARAGRAPH: } \\
\text { RUN IN }\end{array}$ & $\stackrel{\text { no marked. }}{\text { Yyour proof. }}$ & 미 & INDENT 2 EMS & DYour proof. \\
\hline 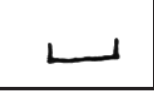 & LOWER & $山$ Your proof. & पIII) & INDENT 3 EMS & पII Your proof. \\
\hline
\end{tabular}




\section{Journal of Applied Physiology 2006 \\ Published by The American Physiological Society \\ This is your pro forma invoice or order form}

(Please keep a copy of this document for your records. This form is not for commercial ordering)

IMPORTANT Order form must be returned within 48 hours of receipt to avoid late charges. Orders received after 48 hours will be charged an additional fee of $25 \%$. Orders received after 30 days will be charged an additional $50 \%$. Reprints containing color figures are available only if ordered before the journal is printed. It is the policy of Cadmus Reprints to issue only one invoice per order. Please print clearly. Please return form whether reprints are ordered or not.

Author Name

Title of Article

Issue of Journal

Number of Pages

Color in Article? Yes / No (Please Circle)

Manuscript \# JAP-00014-2006

Article \# 3122746
Publication Date Symbol $\underline{\text { JAP }}$

Please include the journal name and reprint number or manuscript number on your purchase order or other correspondence.

\section{Reprint and Publication Costs}

Reprint Costs (Please see page 2 for reprint costs/fees.)

Number of reprints ordered

Number of color reprints ordered

\section{Subtotal}

Add appropriate sales tax/GST to subtotal

Add $\$ 32$ for each additional ship location

Total Reprint Due

Publication Fees (Please see page 2 for fees and descriptions.)

Page Charges: \$70 per journal page

Color Figures: $\$ 350$ per color figure

Hard copy color proof: $\$ 75$ per figure

Toll-Free Link: \$150

Member No.

Member Signature
Total Publication
TOTAL TO REM
(FEIN \#:541274108)
Check
al Purchase Order

Checks must be paid in U.S. dollars and drawn on a U.S. Bank.

Credit Card: VISA Am. Exp. MasterCard

Card Number

Expiration Date

Signature:

Cadmus will process credit cards and Cadmus Journal Services will appear on the credit card statement.

Send payment and order form (no express packages) to:

Cadmus Reprints

P.O. Box 751903

Charlotte, NC 28275-1903

Fax order form

to $410-820-9765$

Shipping Address (cannot ship to a P.o. Box.) Please print clearly
Name
Institution
Department
Street
City
Country State $\_$
Quantity
Phone: Day

Additional Shipping Address* (cannot ship to a P.o. Box)
Name
Institution
Department
Street
City State
Country
Quantity
Phone: Day
$*$ Add \$32 for each additional shipping address

Invoice and Credit Card Information

Invoice Address Please complete Invoice address as it appears on credit card statement. Please print clearly

Name

Institution

Department

Street

City

Country

Phone

E-mail Address

Purchase Order No

SIGNATURE REQUIRED: By signing this form the author agrees to accept responsibility for the payment of the mandatory page charges of \$70 per page, reprints ordered, as well as any color charges, late payments, and split shipment charges. If the charges are billed to an institution, the author must assume the responsibility for making the necessary arrangements for the issuance of a formal institutional purchase order. Otherwise, it is understood that the author will bear the cost of these charges. Failure to pay any of these agreed-upon charges could jeopardize future submissions.

AUTHOR Signature

Telephone
Fax

E-mail 


\section{Journal of Applied Physiology (JAP) 2006}

\section{Published by The American Physiological Society \\ REPRINT AND PUBLICATION CHARGES Author rates only. Not to be used for commercial ordering}

Black and White Reprint Prices

\begin{tabular}{|c|c|c|c|c|c|c|}
\hline \multicolumn{7}{|c|}{ Domestic (USA only) } \\
\hline $\begin{array}{c}\text { \# of } \\
\text { Pages }\end{array}$ & 100 & 200 & 300 & 400 & 500 & $\begin{array}{c}\text { Addl } \\
100 \text { ’s }\end{array}$ \\
\hline $1-4$ & $\$ 205$ & $\$ 287$ & $\$ 367$ & $\$ 449$ & $\$ 529$ & $\$ 74$ \\
\hline $5-8$ & $\$ 279$ & $\$ 421$ & $\$ 566$ & $\$ 709$ & $\$ 851$ & $\$ 128$ \\
\hline $9-12$ & $\$ 359$ & $\$ 546$ & $\$ 737$ & $\$ 923$ & $\$ 1,112$ & $\$ 143$ \\
\hline $13-16$ & $\$ 431$ & $\$ 681$ & $\$ 932$ & $\$ 1,182$ & $\$ 1,434$ & $\$ 238$ \\
\hline $17-20$ & $\$ 501$ & $\$ 808$ & $\$ 1,112$ & $\$ 1,418$ & $\$ 1,719$ & $\$ 292$ \\
\hline $21-24$ & $\$ 583$ & $\$ 941$ & $\$ 1,299$ & $\$ 1,658$ & $\$ 2,015$ & $\$ 342$ \\
\hline $25-28$ & $\$ 653$ & $\$ 1,076$ & $\$ 1,497$ & $\$ 1,918$ & $\$ 2,339$ & $\$ 401$ \\
\hline $29-32$ & $\$ 737$ & $\$ 1,210$ & $\$ 1,696$ & $\$ 2,178$ & $\$ 2,662$ & $\$ 459$ \\
\hline
\end{tabular}

\begin{tabular}{|c|c|c|c|c|c|c|}
\hline \multicolumn{7}{|c|}{ International (includes Canada and Mexico) } \\
\hline $\begin{array}{c}\text { \# of } \\
\text { Page }\end{array}$ & 100 & 200 & 300 & 400 & 500 & $\begin{array}{c}\text { Addl } \\
100 \text { 's }\end{array}$ \\
\hline $1-4$ & $\$ 231$ & $\$ 323$ & $\$ 419$ & $\$ 512$ & $\$ 607$ & $\$ 86$ \\
\hline $5-8$ & $\$ 316$ & $\$ 484$ & $\$ 654$ & $\$ 823$ & $\$ 992$ & $\$ 154$ \\
\hline $9-12$ & $\$ 410$ & $\$ 634$ & $\$ 868$ & $\$ 1,089$ & $\$ 1,320$ & $\$ 182$ \\
\hline $13-16$ & $\$ 494$ & $\$ 796$ & $\$ 1,098$ & $\$ 1,401$ & $\$ 1,705$ & $\$ 291$ \\
\hline $17-20$ & $\$ 578$ & $\$ 949$ & $\$ 1,320$ & $\$ 1,689$ & $\$ 2,054$ & $\$ 356$ \\
\hline $21-24$ & $\$ 670$ & $\$ 1,107$ & $\$ 1,544$ & $\$ 1,980$ & $\$ 2,416$ & $\$ 419$ \\
\hline $25-28$ & $\$ 757$ & $\$ 1,268$ & $\$ 1,779$ & $\$ 2,293$ & $\$ 2,801$ & $\$ 492$ \\
\hline $29-32$ & $\$ 852$ & $\$ 1,430$ & $\$ 2,019$ & $\$ 2,606$ & $\$ 3,194$ & $\$ 564$ \\
\hline
\end{tabular}

Minimum order is 100 copies. For articles longer than 32 pages, please consult Cadmus Reprints at 800-407-9190.

\section{Page Charges}

$\$ 70$ per journal page for all pages in the article, whether or not you buy reprints.

\section{Color}

Reprints containing color figures are available. If your article contains color, you must pay subsidized color charges of $\$ 350 /$ fig. (reprint charge is $\$ 1000 /$ fig for those who do not pay promptly), whether or not you buy reprints. These color charges are waived for APS Members who are the first or last author of the paper. If you requested a hard copy color figure proof when you reviewed your S-proof, the charge is $\$ 75$.

\section{Shipping}

Shipping costs are included in the reprint prices. Domestic orders are shipped via UPS Ground service. Foreign orders are shipped via an expedited air service. The shipping address printed on an institutional purchase order always supercedes.

\section{Multiple Shipments}

Orders can be shipped to more than one location. Please be aware that it will cost $\$ 32$ for each additional location.

\section{State Sales Tax and Canadian GST}

Residents of Virginia, Maryland, Pennsylvania, and the District of Columbia are required to add the appropriate sales tax to each reprint order. For orders shipped to Canada, please add 7\% Canadian GST unless exemption is claimed.
Color Reprint Prices

\begin{tabular}{|c|c|c|c|c|c|c|}
\hline \multicolumn{7}{|c|}{ Domestic (USA only) } \\
\hline $\begin{array}{c}\# \text { of } \\
\text { Pages }\end{array}$ & 100 & 200 & 300 & 400 & 500 & $\begin{array}{l}\text { Addl } \\
100 \text { 's }\end{array}$ \\
\hline $1-4$ & $\$ 305$ & $\$ 487$ & $\$ 667$ & $\$ 849$ & $\$ 1,029$ & $\$ 175$ \\
\hline $5-8$ & $\$ 379$ & $\$ 621$ & $\$ 866$ & $\$ 1,109$ & $\$ 1,351$ & $\$ 228$ \\
\hline $9-12$ & $\$ 459$ & $\$ 746$ & $\$ 1,037$ & $\$ 1,323$ & $\$ 1,612$ & $\$ 243$ \\
\hline $13-16$ & $\$ 531$ & $\$ 881$ & $\$ 1,232$ & $\$ 1,582$ & $\$ 1,934$ & $\$ 338$ \\
\hline $17-20$ & $\$ 601$ & $\$ 1,008$ & $\$ 1,412$ & $\$ 1,818$ & $\$ 2,219$ & $\$ 392$ \\
\hline $21-24$ & $\$ 683$ & $\$ 1,141$ & $\$ 1,599$ & $\$ 2,058$ & $\$ 2,515$ & $\$ 442$ \\
\hline $25-28$ & $\$ 753$ & $\$ 1,276$ & $\$ 1,797$ & $\$ 2,318$ & $\$ 2,839$ & $\$ 501$ \\
\hline $29-32$ & $\$ 837$ & $\$ 1,410$ & $\$ 1,996$ & $\$ 2,578$ & $\$ 3,162$ & $\$ 559$ \\
\hline
\end{tabular}

\begin{tabular}{|c|c|c|c|c|c|c|}
\hline \multicolumn{7}{|c|}{ International (includes Canada and Mexico) } \\
\hline $\begin{array}{c}\text { \# of } \\
\text { Pages }\end{array}$ & 100 & 200 & 300 & 400 & 500 & $\begin{array}{c}\text { Addl } \\
100 ’ s\end{array}$ \\
\hline $1-4$ & $\$ 331$ & $\$ 523$ & $\$ 719$ & $\$ 912$ & $\$ 1,107$ & $\$ 186$ \\
\hline $5-8$ & $\$ 416$ & $\$ 684$ & $\$ 954$ & $\$ 1,223$ & $\$ 1,492$ & $\$ 254$ \\
\hline $9-12$ & $\$ 510$ & $\$ 834$ & $\$ 1,168$ & $\$ 1,489$ & $\$ 1,820$ & $\$ 282$ \\
\hline $13-16$ & $\$ 594$ & $\$ 996$ & $\$ 1,398$ & $\$ 1,801$ & $\$ 2,205$ & $\$ 391$ \\
\hline $17-20$ & $\$ 678$ & $\$ 1,149$ & $\$ 1,620$ & $\$ 2,089$ & $\$ 2,554$ & $\$ 456$ \\
\hline $21-24$ & $\$ 770$ & $\$ 1,307$ & $\$ 1,844$ & $\$ 2,380$ & $\$ 2,916$ & $\$ 519$ \\
\hline $25-28$ & $\$ 857$ & $\$ 1,468$ & $\$ 2,079$ & $\$ 2,693$ & $\$ 3,301$ & $\$ 592$ \\
\hline $29-32$ & $\$ 952$ & $\$ 1,630$ & $\$ 2,319$ & $\$ 3,006$ & $\$ 3,694$ & $\$ 664$ \\
\hline
\end{tabular}

TOLL-FREE LINK

A link can be created from a url of your choice to your article online so that readers accessing your article from your url can do so without a subscription. The cost is $\$ 150$. This is especially useful if your article contains electronic supplemental material. For more information, please click on this link:

http://www.the-aps.org/publications/sprooflink.pdf

\section{Ordering}

Please fax your order form and purchase order to 410-820-9765. Prepayment of checks should be mailed to address below:

\author{
Cadmus Reprints \\ P.O. Box 751903 \\ Charlotte, NC 28275-1903
}

Note: Do not send express packages to this location. FEIN \#:541274108

Please direct all inquiries to:
Mary Leonard
$800-407-9190$ (toll free number)
410-819-3912 (direct number)
410-820-9765 (FAX number)
LeonardM@cadmus.com 


\title{
Objective evaluation of changes in left ventricular and atrial volumes during parabolic flight using real-time three-dimensional echocardiography
}

\author{
E. G. Caiani, ${ }^{1}$ L. Sugeng, ${ }^{2}$ L. Weinert, ${ }^{2}$ A. Capderou, ${ }^{3}$ R. M. Lang, ${ }^{2}$ and P. Vaïda $^{4}$ \\ ${ }^{1}$ Dipartimento di Bioingegneria, Politecnico di Milano, Milan, Italy; ${ }^{2}$ Noninvasive Cardiac Imaging Laboratory, University \\ of Chicago, Chicago, Illinois; ${ }^{3}$ Université Paris Sud, Unité Propre de Recherche de l'Enseignement Supérieur Équipe \\ d'Accueil 2397, CCML, Physiologie, Le Plessis Robinson, France; and ${ }^{4}$ Université Bordeaux 2, Unité Propre de \\ Recherche de l'Enseignement Supérieur Équipe d'Accueil 518, Médecine Aérospatiale, Bordeaux, France
}

Submitted 5 January 2006; accepted in final form 31 March 2006

Caiani, E. G., L. Sugeng, L. Weinert, A. Capderou, R. M. Lang, and P. Vaïda. Objective evaluation of changes in left ventricular and atrial volumes during parabolic flight using real-time three-dimensional echocardiography. J Appl Physiol 101: 000-000, 2006. First published April 6, 2006; doi:10.1152/japplphysiol.00014.2006.—We tested the feasibility of real-time three-dimensional (3D) echocardiographic (RT3DE) imaging to measure left heart volumes at different gravity during parabolic flight and studied the effects of lower body

AQ: 1 negative pressure (LBNP) as a countermeasure. Weightlessness-related changes in cardiac function have been previously studied during

AQ: 2 spaceflights using both 2D and 3D echocardiography. Several technical factors, such as inability to provide real-time analysis and the need for laborious endocardial definition, have limited its usefulness. RT3DE imaging overcomes these limitations by acquiring real-time pyramidal data sets encompassing the entire ventricle. RT3DE data sets were obtained (Philips 7500, X3) during breath hold in 16 unmedicated normal subjects in upright standing position at different gravity phases during parabolic flight (normogravity, $1 \mathrm{G}_{\mathrm{z}}$; hypergravity, $1.8 \mathrm{G}_{\mathrm{z}}$; microgravity, $0 \mathrm{G}_{\mathrm{z}}$ ), with $\mathrm{LBNP}$ applied $(-50 \mathrm{mmHg})$ at $0 \mathrm{G}_{\mathrm{z}}$ in selected parabolas. RT3DE imaging during parabolic flight was feasible in 14 of 16 subjects. Data were analyzed (Tomtec) to quantify left ventricular (LV) and atrial (LA) volumes at end diastole and end systole, which significantly decreased at $1.8 \mathrm{G}_{\mathrm{z}}$ and increased at $0 \mathrm{G}_{\mathrm{z}}$. While ejection fraction did not change with gravity, stroke volume was reduced by $16 \%$ at $1.8 \mathrm{G}_{\mathrm{z}}$ and increased by $20 \%$ at $0 \mathrm{G}_{\mathrm{z}}$, but was not significantly different from $1 \mathrm{G}_{\mathrm{z}}$ values with LBNP. RT3DE during parabolic flight is feasible and provides the basis for accurate quantification of LV and LA volume changes with gravity. As LBNP counteracted the increase of LV and LA volumes caused by changes in venous return, it may be effectively used for preventing

AQ: 3 cardiac dilatation during $0 \mathrm{G}_{\mathrm{z}}$.

weightlessness; countermeasures

DURING SPACEFLIGHT, CHANGES in gravity $\left(\mathrm{G}_{\mathrm{z}}\right.$, head-to-foot acceleration) affect the cardiovascular system by causing fluid shifts from the lower extremities toward the head and thorax, thus altering central filling volumes (FVs) and pressures $(15,16,23,31)$. These hemodynamic alterations, which directly influence heart chamber dimensions and function, are responsible for many of the adverse effects associated with the postflight orthostatic intolerance observed in astronauts (20-22).

The potential for commercial spaceflight has made a precise understanding of the early cardiovascular adaptation to weightlessness important. As more individuals have the opportunity

Address for reprint requests and other correspondence: E. G. Caiani, Politecnico di Milano, Dipartimento di Bioingegneria, Piazza L. da Vinci, 32, 20133 Milano, Italy (e-mail: caiani@biomed.polimi.it). to fly in space, standards will need to be set to decide what level of cardiovascular function is needed to tolerate the acute headward fluid shift that occurs in weightlessness. Some individuals with nondistensible ventricles potentially could develop pulmonary edema upon entering weightlessness. Measurements of the expected changes in ventricular volumes, atrial volumes, and peak filling rate (PFR) upon entering weightlessness are needed to help set appropriate standards. In addition, certain countermeasures, like lower body negative pressure (LBNP) devices $(24,38)$, could be used to reduce the fluid shift and prevent or treat adverse events.

Moreover, the evaluation of cardiovascular physiology under different gravitational loads may provide some crossover benefits to clinical medicine on Earth. Ground-based studies represent an invaluable opportunity to investigate human physiology during simulated microgravity $\left(0 \mathrm{G}_{\mathrm{z}}\right)$ conditions. Among them, parabolic flight presents a unique opportunity to study the immediate physiological adaptations of the cardiovascular system to different gravity conditions.

Two-dimensional (2D) echocardiography (2DE) has been the principal imaging modality used in space programs to evaluate changes in the cardiovascular system and to test the effectiveness of countermeasures employed to alleviate these changes (34). Using 2DE, patterns of adaptation of left ventricular ( $\mathrm{LV}$ ) dimensions to $0 \mathrm{G}_{\mathrm{z}}$ during short- and long-term missions have been previously described $(3,10,11,25,37,41)$. However, although 2DE is routinely used in clinical practice to measure heart chamber dimensions, wall thickness, and function, this imaging technique is limited because it relies on correct probe positioning to avoid acquisition of foreshortened apical views. In addition, derivation of volumetric parameters from multiple $2 \mathrm{D}$ views requires the use of geometric models, which may introduce additional errors $(19,43,49)$.

In an attempt to circumvent these constraints, Zoghbi et al. (50) have developed a nongeometric three-dimensional (3D) echocardiographic (3DE) method by acquiring multiple shortaxis $2 \mathrm{DE}$ images of the $\mathrm{LV}$ from a single pivoting point and reconstructing the volume offline. Using this approach, 3DE was previously used in space (Spacelab Life Sciences-1 and -2 missions) to measure LV volumes (8). However, this methodology is limited by several factors, such as cumbersome data acquisition required for offline 3D reconstruction and the need for tedious offline manual tracings of endocardial borders in multiple planes.

\footnotetext{
The costs of publication of this article were defrayed in part by the payment of page charges. The article must therefore be hereby marked "advertisement" in accordance with 18 U.S.C. Section 1734 solely to indicate this fact.
} 
AQ: 7 Fig. 1. Left: parabolic flight trajectory (solid line) and corresponding gravity $\left(\mathrm{G}_{\mathrm{z}}\right)$ along the parabola (shaded dashed line). Right: experimental setup onboard the Airbus. On the left, in the foreground, is the lower body negative pressure (LBNP) chamber and, in the background, the ultrasound equipment embedded into a safety rack. On the right are a bench and straps on the floor utilized to stabilize the sonographer to prevent free floating during microgravity $\left(0 \mathrm{G}_{\mathrm{z}}\right) \cdot 1 \mathrm{G}_{\mathrm{z}}$, normogravity; $1.8 \mathrm{G}_{\mathrm{z}}$, hypergravity.

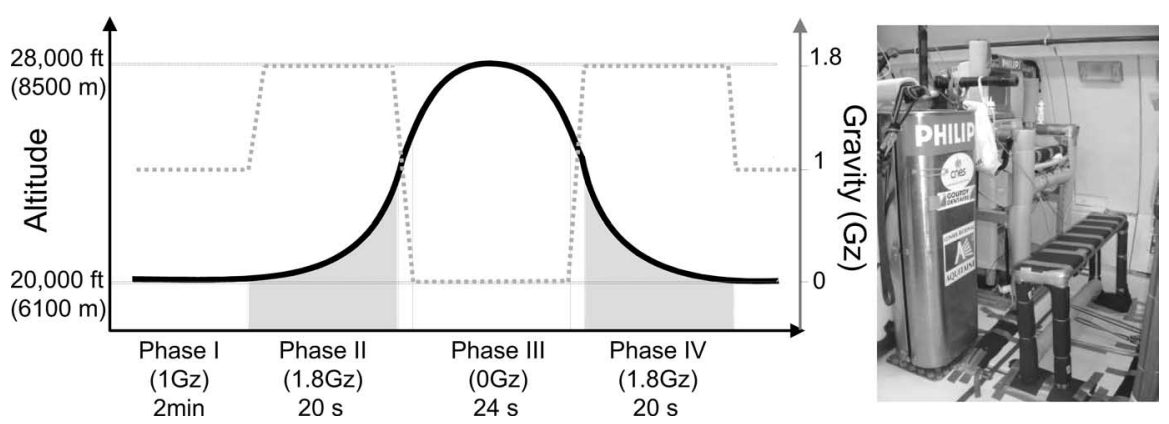

The recent development of second-generation full-matrix array transducers, capable of high spatial resolution and near real-time acquisition of wide-angled pyramidal 3DE data sets, has overcome many of the limitations of $2 \mathrm{DE}$, and thus provided the basis for accurate estimates of LV volumes (13, 26, 30), mass (36), and function (18).

We hypothesized that real-time 3DE (RT3DE) could be used in a weightlessness environment for accurate quantification of the adaptations in LV and left atrial (LA) dimensions in response to changes in gravity. Accordingly, the aims of this study were 1 ) to test the feasibility of RT3DE imaging of the LV and LA in a weightlessness environment; 2) to evaluate the changes in LV and LA volumes occurring with changes in gravity during parabolic flight; and 3 ) to test the effectiveness of the LBNP device in reducing LV and LA volumes during 0 $\mathrm{G}_{\mathrm{z}}$ by counteracting the decrease in hydrostatic pressure in the lower body.

\section{METHODS}

Subjects. Eighteen normal volunteers (13 men and 5 women, mean age $38 \pm 14 \mathrm{yr}$ ) without a history of cardiovascular disease were enrolled in the study, after providing written, informed consent. All subjects were screened before participation to ensure adequate acoustic windows, even when imaging in the upright position. After completion of the preliminary screening, 16 out of the 18 volunteers (12 men and 4 women, mean age $36 \pm 13 \mathrm{yr}$ ) were selected. None of the subjects were taking medication before and/or during the flights. This study was approved by both the French [Centre National d'Etudes Spatiales (CNES)] and the European Space Agency (ESA).

Equipment and protocol. The study was conducted during two parabolic flight campaigns (CNES: November 2004, ESA: October 2005), on board of the ESA-CNES ZeroG Airbus A300 aircraft, performed in Bordeaux, France. Each flight lasted 2.5-3 h and included 31 parabolas.

Instantaneous gravity was continuously measured using the aircraft's accelerometer. Gravity variations during a parabolic flight trajectory include four consecutive phases (Fig. 1, left): normogravity $\mathbf{F}$ (phase I: head-to-foot acceleration, $1 \mathrm{G}_{\mathrm{z}}$ ) before parabola initiation; mild hypergravity (phase II: $1.8 \mathrm{G}_{\mathrm{z}}, 20 \mathrm{~s}$ ) during the ascending phase of the parabola; microgravity (phase III: $0 \mathrm{G}_{\mathrm{z}}, 24 \mathrm{~s}$ ) at the top of the parabola; and a second period of mild hypergravity (phase IV: $1.8 \mathrm{G}_{\mathrm{z}}$, $20 \mathrm{~s})$ during the descending phase of the parabola. Between consecutive parabolas, a period of steady state (at $1 \mathrm{G}$ ) persisted for a minimum of $2 \mathrm{~min}$.

Each subject was imaged in the upright standing position during a maximum of 12 consecutive parabolas, with the abdomen and lower extremities placed inside a LBNP chamber (Fig. 1, right). To allow the lower limbs to stay relaxed (to maximize blood and fluid movement to/from the lower body), subjects were placed on a saddle within the LBNP chamber with the arms secured to the structure by straps. To test the effectiveness of LBNP in counteracting the effects of $0 G_{z}$ by reducing venous return, a negative pressure of $-50 \mathrm{mmHg}$ was applied during the $0 \mathrm{G}_{\mathrm{z}}$ phase in selected parabolas (from 3 to 5 ) in random order.

RT3DE imaging. Transthoracic RT3DE was performed from the apical window, with a full-matrix array transducer $(\mathrm{X} 3,2-4 \mathrm{MHz})$ in the harmonic mode using a SONOS 7500 (Philips Medical Systems, Andover, MA). To avoid body movement during acquisition, both subject and sonographer were stabilized against free floating. A second operator aided in optimizing image quality (gain and compression) and completing data acquisition.

For each gravity phase of the parabola, one RT3DE data set representing one cardiac cycle (frame rate $20 \mathrm{~Hz}$ ) was acquired during a breath hold, while avoiding Mueller or Valsalva maneuvers, and thus trying to minimize changes in intrathoracic pressure. Image acquisition was performed using the wide-angled acquisition mode, in
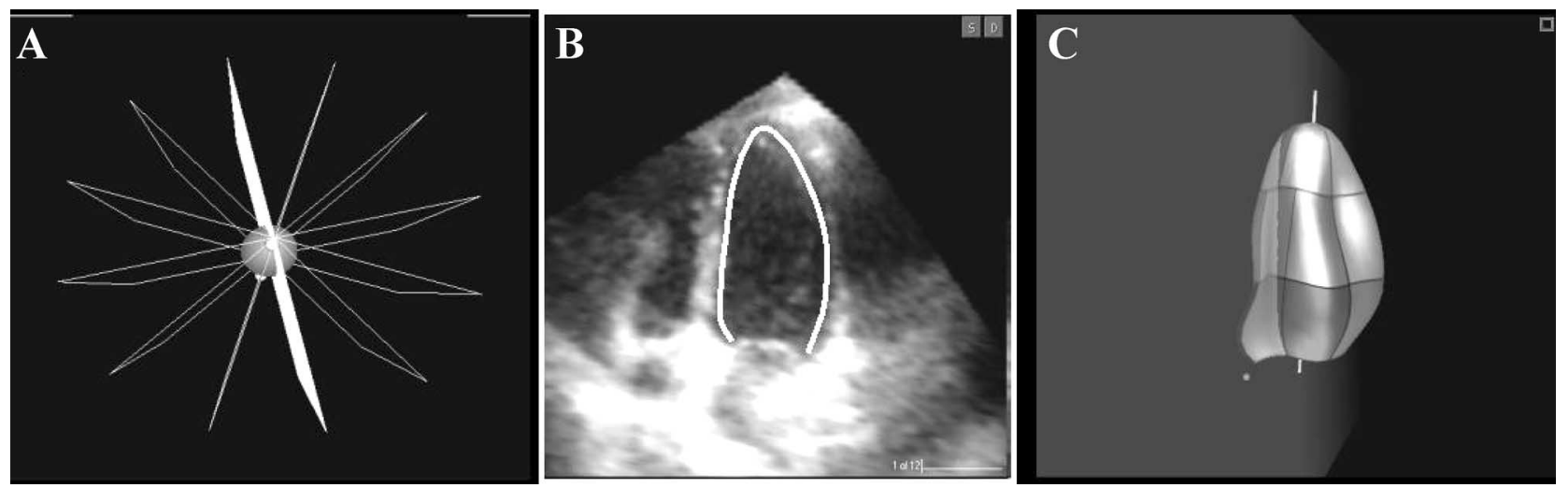

Fig. 2. Left ventricular (LV) volume analysis procedure (see text for details). $A$ : LV long-axis and 6 equi-angled two-dimensional (2D) cut-planes selection; $B$ : semiautomatic tracing of the LV endocardial contour in each cut-plane; $C$ : automated computation of the three-dimensional (3D) cast representing the LV cavity volume. 


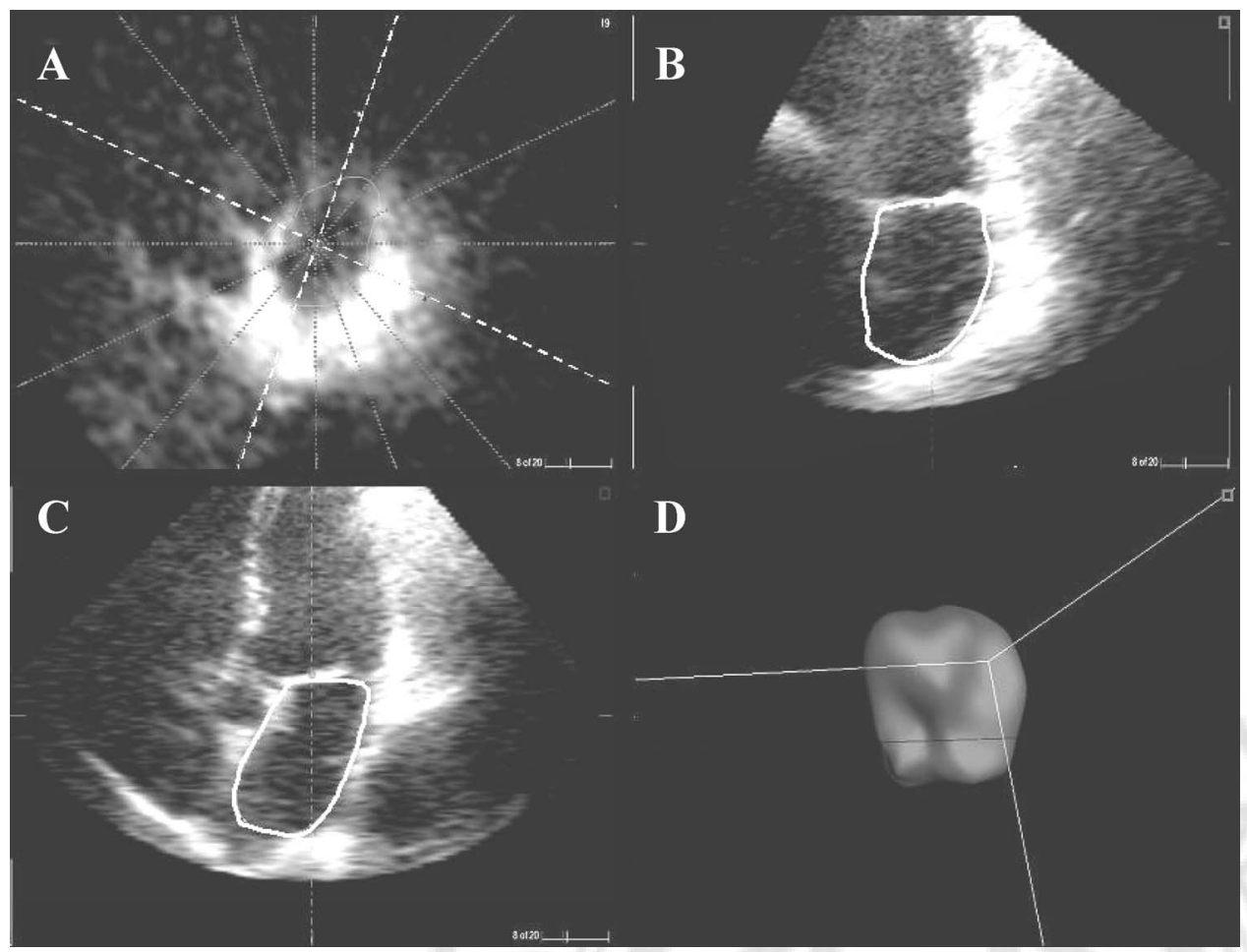

Fig. 3. Left atrial (LA) volume analysis procedure. A: LA long-axis and 8 equi-angled 2D cut-planes selection; $B$ and $C$ : semiautomatic tracing of the LV endocardial contour in each set of two orthogonal cut-planes; $D$ : automated computation of the 3D cast representing LA cavity volume.

which four wedge-shaped subvolumes $\left(93^{\circ} \times 21^{\circ}\right)$ were obtained over eight cardiac cycles with ECG gating. In this mode, each subvolume acquisition is triggered to the R-wave of every other heartbeat to allow sufficient time for the probe to be recalibrated and each subvolume stored. Particular care was taken to include the entire $\mathrm{LV}$ and atrium within the pyramidal 3D scan volume.

Image acquisition at $1 \mathrm{G}_{\mathrm{z}}$ was performed $10 \mathrm{~s}$ before the initiation of phase II, while image acquisition at $1.8 \mathrm{G}_{\mathrm{z}}, 0 \mathrm{G}_{\mathrm{z}}$, and final $1.8 \mathrm{G}_{\mathrm{z}}$ was performed $5 \mathrm{~s}$ after the beginning of phases II, III, and IV, respectively, to avoid data acquisition during the short initial transition during which abrupt changes in cardiac volumes and heart rate may occur.

$R T 3 D E$ volume analysis. The RT3DE data sets acquired in each subject during each phase of the parabola (i.e., I, II, III and IV) were first visually inspected. Only parabolas with proper LV and LA endocardial visualization in each gravity phase, assessed in two orthogonal cut-planes, corresponding to apical two- and four-chamber views, were selected for analysis. The RT3DE data sets were analyzed in random order by an expert reader, blinded to the subject's identity and to the gravity phase.

To quantify LV dimensions, each data set was analyzed offline using commercially available software (4D LV Analysis, TomTec), previously described in detail (30). Briefly, after identifying the LV long axis, six equi-angled long-axis cut-planes were automatically generated (Fig. $2 A$ ). To define the mitral valve plane in each of these cut-planes, the mitral valve annulus was identified in the end-diastolic (ED) and end-systolic (ES) frames. An ellipse was then placed in the ED and ES frames in each of the six selected long-axis cut-planes, manually adapting its shape and angular position to fit as close as possible to the endocardial border. Following this initialization phase, the semiautomatic endocardial contour detection procedure was applied, resulting in a detected endocardial contour for each cut-plane and for each consecutive frame throughout the cardiac cycle (Fig. 2B). To verify the correctness of the border detection, each cut-plane was then visualized in the cine mode with the detected contour overimposed, to allow the operator to perform manual adjustments, when necessary. Finally, for each frame, the contours of the six cut-planes
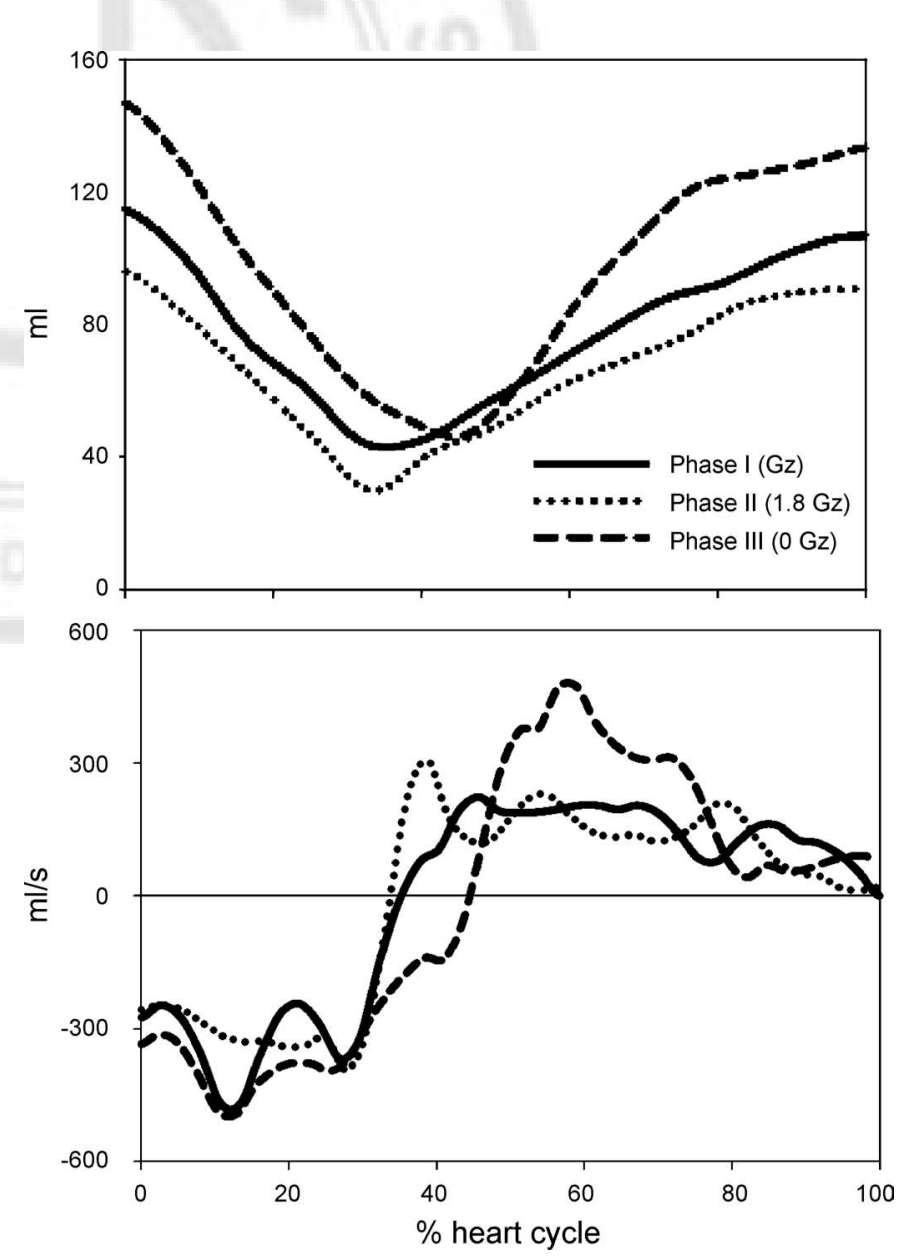

Fig. 4. LV volume vs. time curves (top) and corresponding first derivatives (bottom), both expressed in percentage of the heart cycle, obtained from a subject during the first three $\mathrm{G}_{\mathrm{z}}$ phases of the parabola. 
were then interpolated and displayed as a wire-frame model in the 3D space (Fig. 2C), from which the enclosed LV volume was computed using Gaussian quadrature formulas.

Global LV volume vs. time curves were obtained, from which ED (EDV) and ES volumes (ESV), defined as the maximum and the minimum volume, respectively, were measured. Stroke volume (SV) was computed as the difference between EDV and ESV, and ejection fraction (EF) was derived as $100 *$ SV/EDV. Moreover, the first derivative of LV volume vs. time was computed, and the PFR and peak ejection rates (PER) were calculated.

To quantify the LA volumes in the ED and ES frames, the same RT3DE data sets were analyzed offline using commercial software (EchoView, TomTec). After selecting the LA long axis, eight equiangled 2D long-axis cut-planes were generated (Fig. 3A), and, in each pair of orthogonal planes, manual tracing of the atrial endocardial borders was performed using an interactive spline interpolation algorithm (Fig. 3, $B$ and $C$ ). After interpolation of the traced contours in a 3D wire-frame model (Fig. 3D), the LA cavity volume was calculated automatically (29).

The LA volume computed in the ES frame was defined as $\mathrm{LA}_{\max }$, whereas the LA volume computed in the ED frame was defined as $\mathrm{LA}_{\text {min }}$. The LA reservoir function was assessed using FV, defined as $\left(\mathrm{LA}_{\max }-\mathrm{LA}_{\min }\right)$, and the expansion index $(\mathrm{EI})$, defined as $100 *$ $\mathrm{FV} / \mathrm{LA}_{\min }$. The overall diastolic emptying index (DEI) was calculated as $100 * \mathrm{FV} / \mathrm{LA}_{\max } * 100$ (44). Moreover, to evaluate possible asymmetries in LA shape changes with $0 \mathrm{G}_{\mathrm{z}}$, the LA diameters along its major (D2, antero-posterior dimension) and minor (D1, mediallateral dimension) axes were computed at $1 \mathrm{G}_{\mathrm{z}}$ and $0 \mathrm{G}_{\mathrm{z}}$.

Statistical analysis. LV and LA volumes and derived parameters, normalized by their value at $1 \mathrm{G}_{\mathrm{z}}$, were averaged for all subjects in each gravity phase. Data were displayed as means \pm SD. One-way ANOVA with repeated measures $(P<0.05$, Tukey test) was used to test the differences between gravity phases. The effectiveness of LBNP in reducing changes in LV, LA volumes, and derived parameters at $0 \mathrm{G}_{\mathrm{z}}$ was tested by paired Student's $t$-test. Differences were considered significant for $P<0.05$ compared with the results at $0 \mathrm{G}_{\mathrm{z}}$ obtained without LBNP.

\section{RESULTS}

RT3DE imaging during parabolic flight was feasible in 14 of 16 subjects ( $87.5 \%$ of success), in which RT3DE data sets were acquired for each gravity phase $\left(1 \mathrm{G}_{\mathrm{z}}\right.$, first $1.8 \mathrm{G}_{\mathrm{z}}, 0 \mathrm{G}_{\mathrm{z}}$, second $1.8 \mathrm{G}_{\mathrm{z}}$ ). In the remaining two subjects, adequate visualization of the LV during all gravity phases of the parabola was difficult due to unpredictable shifting of the heart within the chest cavity. In these subjects, repositioning of the probe required more time than the $20 \mathrm{~s}$ available for image acquisition during each phase of the parabola.

Of these 14 subjects, only 10 had also the RT3DE data sets acquired during $0 \mathrm{G}_{\mathrm{z}}$ with LBNP activated. In the remaining 4 of 14 subjects, this data acquisition was not possible due to subjects experiencing motion sickness (3 of 14), and due to flight interruption caused by weather conditions (1 of 14).

Quantitative analysis of LV and LA chambers was feasible in all RT3DE data sets selected for analysis. The time required to analyze a complete RT3DE data set to compute the LV volume was $\sim 15 \mathrm{~min}$, whereas the time required to analyze a single frame to measure the LA volume was $\sim 3 \mathrm{~min}$. Results obtained from the analysis of up to three parabolas in each subjects were averaged to take into account intrasubject variability.

Figure 4 shows LV volume vs. time curves with the corre- F4 sponding first derivatives computed in a same subject during 1 $\mathrm{G}_{\mathrm{z}}, 1.8 \mathrm{G}_{\mathrm{z}}$, and $0 \mathrm{G}_{\mathrm{z}}$. Compared with the $1 \mathrm{G}_{\mathrm{z}}$ curve, an upward shift of the $L V$ volume curve was noted at $0 \mathrm{G}_{\mathrm{z}}$. In contrast, a downward shift of the $\mathrm{LV}$ volume curve was seen at $1.8 \mathrm{G}_{\mathrm{z}}$. Also, an increase in PFR was evident during $0 \mathrm{G}_{\mathrm{z}}$. Figure 5 F5 shows an example of the LV (top) and LA (bottom) 3D ED and
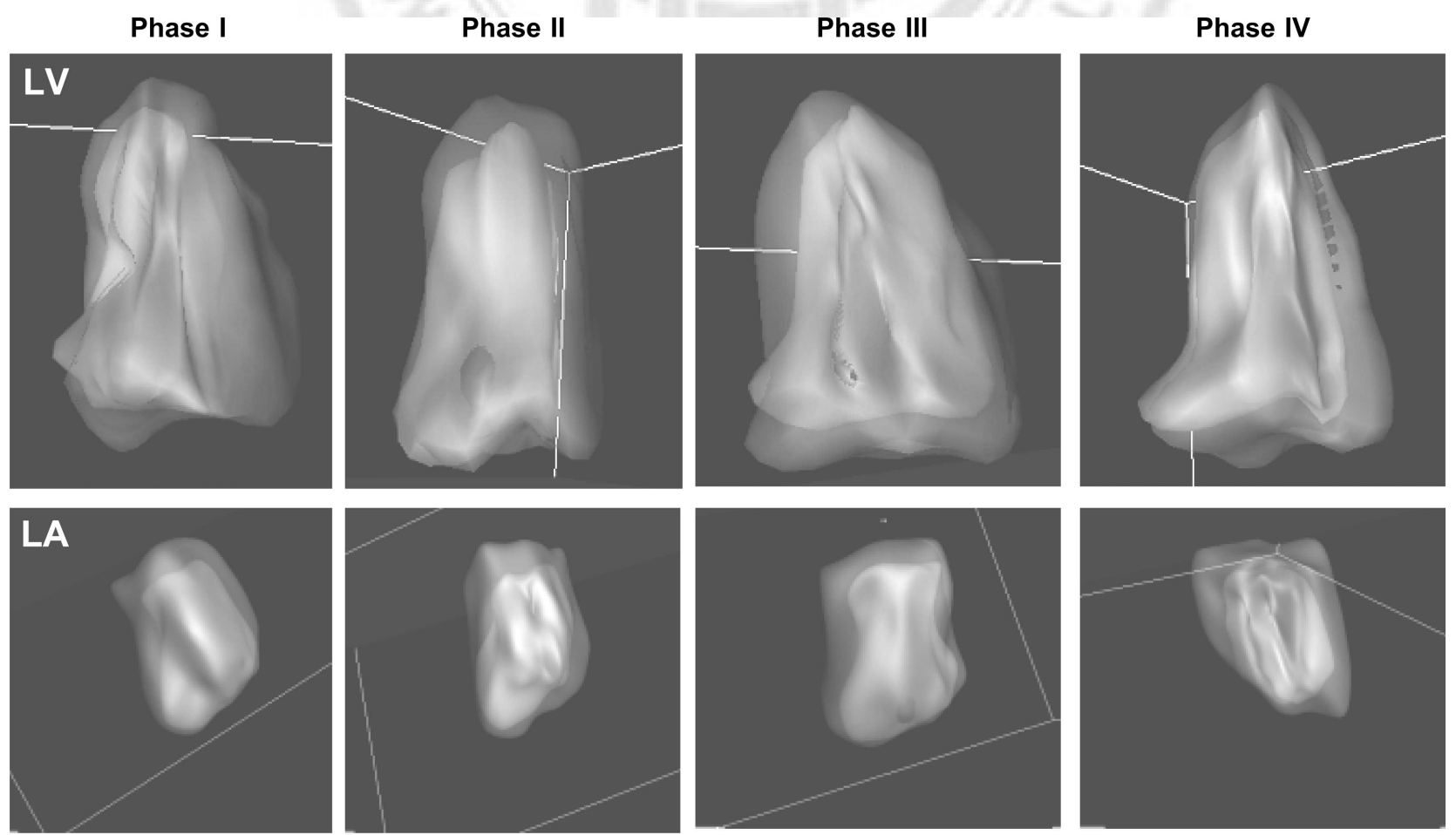

Fig. 5. LV and LA 3D casts obtained from the same subject, visualized using the same zooming scale and orientation, during the different gravity phases of the parabola. In each cast, end-diastolic (light gray) and end-systolic (white shaded) volumes are shown contemporaneously using transparency. 
Table 1. Left ventricular and atrial function parameters computed in 14 normal subjects during the four phases of the parabola

\begin{tabular}{|c|c|c|c|c|}
\hline & Phase I ( $\left.1 \mathrm{G}_{\mathrm{z}}\right)$ & Phase II $\left(1.8 \mathrm{G}_{\mathrm{z}}\right)$ & Phase III $\left(0 \mathrm{G}_{\mathrm{z}}\right)$ & Phase IV $\left(1.8 \mathrm{G}_{\mathrm{z}}\right)$ \\
\hline LV ESV, ml & $29 \pm 9$ & $23 \pm 13 *(-24 \%)$ & $35 \pm 13 *(+23 \%)$ & $24 \pm 13(-21 \%)$ \\
\hline LV SV, ml & $58 \pm 19$ & $49 \pm 21 *(-16 \%)$ & $69 \pm 25 \dagger(+20 \%)$ & $57 \pm 23(-2 \%)$ \\
\hline LV PFR, $\mathrm{ml} / \mathrm{s}$ & $255 \pm 65$ & $221 \pm 70(-13 \%)$ & $335 \pm 102 *(31 \%)$ & $278 \pm 89(+8 \%)$ \\
\hline LV PER, $\mathrm{ml} / \mathrm{s}$ & $-325 \pm 120$ & $-289 \pm 122(-5 \%)$ & $-417 \pm 128 *(37 \%)$ & $-431 \pm 192(+30 \%)$ \\
\hline $\mathrm{LA}_{\max }, \mathrm{ml}$ & $40 \pm 12$ & $26 \pm 9 *(-34 \%)$ & $58 \pm 14 \dagger(+41 \%)$ & $34 \pm 17(-16 \%)$ \\
\hline DEI, \% & $53 \pm 8$ & $49 \pm 8(-5 \%)$ & $60 \pm 7 *(+16 \%)$ & $51 \pm 19(-5 \%)$ \\
\hline EI, \% & $117 \pm 42$ & $101 \pm 35(-6 \%)$ & $158 \pm 44 *(+31 \%)$ & $133 \pm 92(+6 \%)$ \\
\hline
\end{tabular}

Values are means $\pm S D$. In parentheses, the mean percentage of variation with respect to normogravity $\left(1 \mathrm{G}_{\mathrm{z}}\right)$ value is reported. $1.8 \mathrm{G}_{\mathrm{z}}$, hypergravity; $0 \mathrm{G}_{\mathrm{z}}$, microgravity; LV, left ventricular; EDV, end-diastolic volume; ESV, end-systolic volume; SV, stroke volume; EF, ejection fraction; PFR, peak filling rate; PER, peak ejection rate; $\mathrm{LA}_{\max }$, left atrial volume at ventricular end-systole; $\mathrm{LA}_{\min }$, left atrial volume at ventricular end-diastole; DEI, diastolic emptying index; EI, expansion index. ${ }^{*} P<0.05$ vs. $1 \mathrm{G}_{\mathrm{z} .} \dagger P<0.01$ vs. $1 \mathrm{G}_{\mathrm{z}}$.

ES casts obtained in the same subject during the different phases of the parabola: during $1.8 \mathrm{G}_{\mathrm{z}}$, a shrinking of both the $\mathrm{LV}$ and atrium was observed compared with $1 \mathrm{G}_{\mathrm{z}}$, while an AQ: 4 enlargement was seen during the $0 \mathrm{G}_{\mathrm{z}}$ phase.

Significant changes in both LV and LA volumes were measured during the different phases of the parabola (Table 1). Compared with $1 \mathrm{G}_{\mathrm{z}}$ values, both ED and ES LV volumes decreased by 19 and $24 \%$, respectively, during $1.8 \mathrm{G}_{\mathrm{z}}$, and increased of 19 and $23 \%$, respectively, during $0 \mathrm{G}_{\mathrm{z}}$. These changes resulted in a reduction of SV of $16 \%$ during $1.8 \mathrm{G}_{\mathrm{z}}$ and an increase of $20 \%$ during $0 \mathrm{G}_{\mathrm{z}}$, while EF did not change with gravity. Though PFR and PER did not change at $1.8 \mathrm{G}_{\mathrm{z}}$, these parameters increased by 31 and $37 \%$, respectively, during $0 \mathrm{G}_{\mathrm{z}}$, compared with $1 \mathrm{G}_{\mathrm{z}}$ values (Fig. 6).

Compared with $1 \mathrm{G}_{\mathrm{z}}$, both $\mathrm{LA}_{\max }$ and $\mathrm{LA}_{\min }$ volumes decreased by 34 and $29 \%$, respectively, during $1.8 \mathrm{G}_{\mathrm{z}}$, and
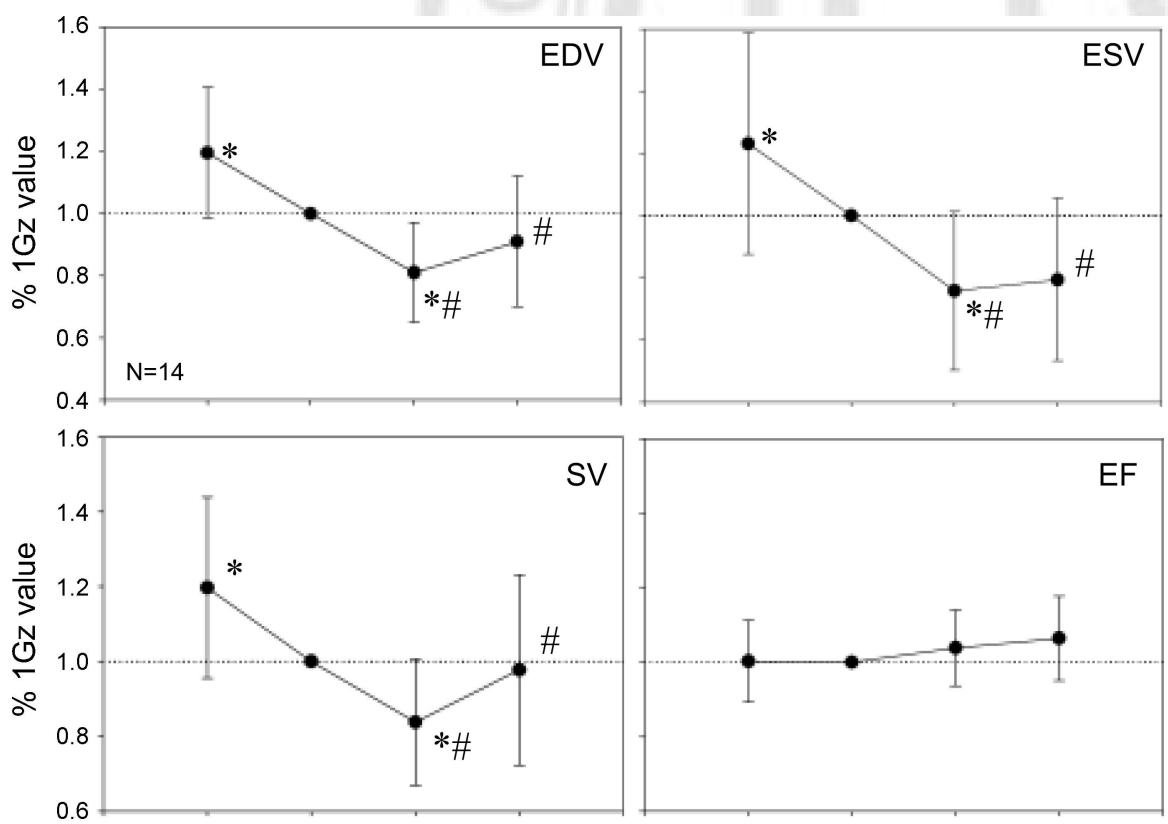

Fig. 6. Average $\pm S D$ of $L V$ parameters measured in 14 subjects during the different gravity phases $\left[0 \mathrm{G}_{\mathrm{z}}\right.$, $1 \mathrm{G}_{\mathrm{z}}, 1.8 \mathrm{G}_{\mathrm{z}}, 1.8 \mathrm{G}_{\mathrm{z}}$ end (second hypergravity phase)] along the parabola. $* P<0.05$ vs. $1 \mathrm{G}_{\mathrm{z}} . \# P<0.05$ vs. $0 \mathrm{G}_{\mathrm{z}}$. All data in each subject have been normalized to the corresponding $1 \mathrm{G}_{\mathrm{z}}$ value. $\mathrm{EDV}$, end-diastolic volume; ESV, end-systolic volume; SV, stroke volume; EF, ejection fraction; PFR, peak filling rate; PER, peak ejection rate.
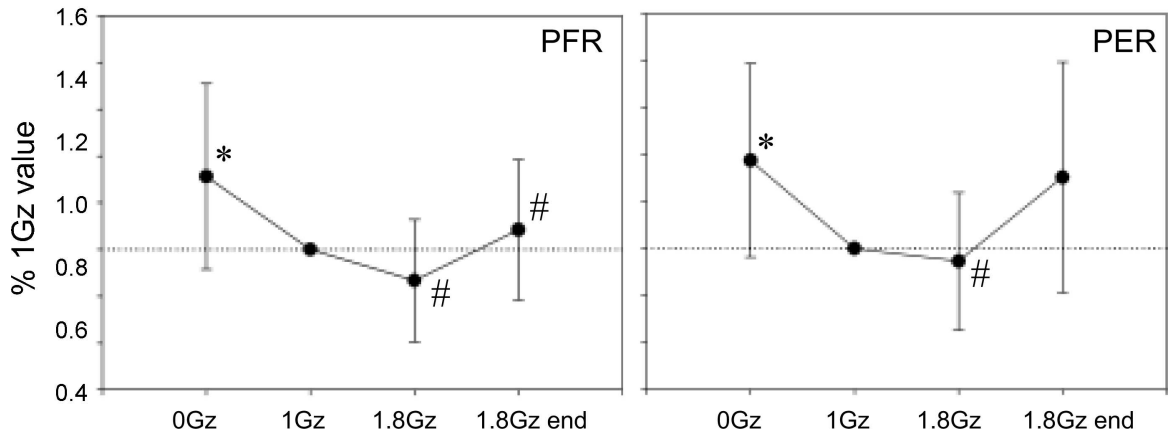
Fig. 7. Average \pm SD of LA parameters measured in 14 subjects during the different gravity phases along the parabola. $* P<0.05$ vs. $1 \mathrm{G}_{\mathrm{z}}$. $\# P<0.05$ vs. $0 \mathrm{G}_{\mathrm{z}}$. All data in each subject have been normalized to the corresponding $1 \mathrm{G}_{\mathrm{z}}$ value. $\mathrm{LA}_{\max }$, LA volume at end-systole; $\mathrm{LA}_{\min }$, LA volume at end-diastole; FV, filling volume; DEI, diastolic emptying index; EI, expansion index.
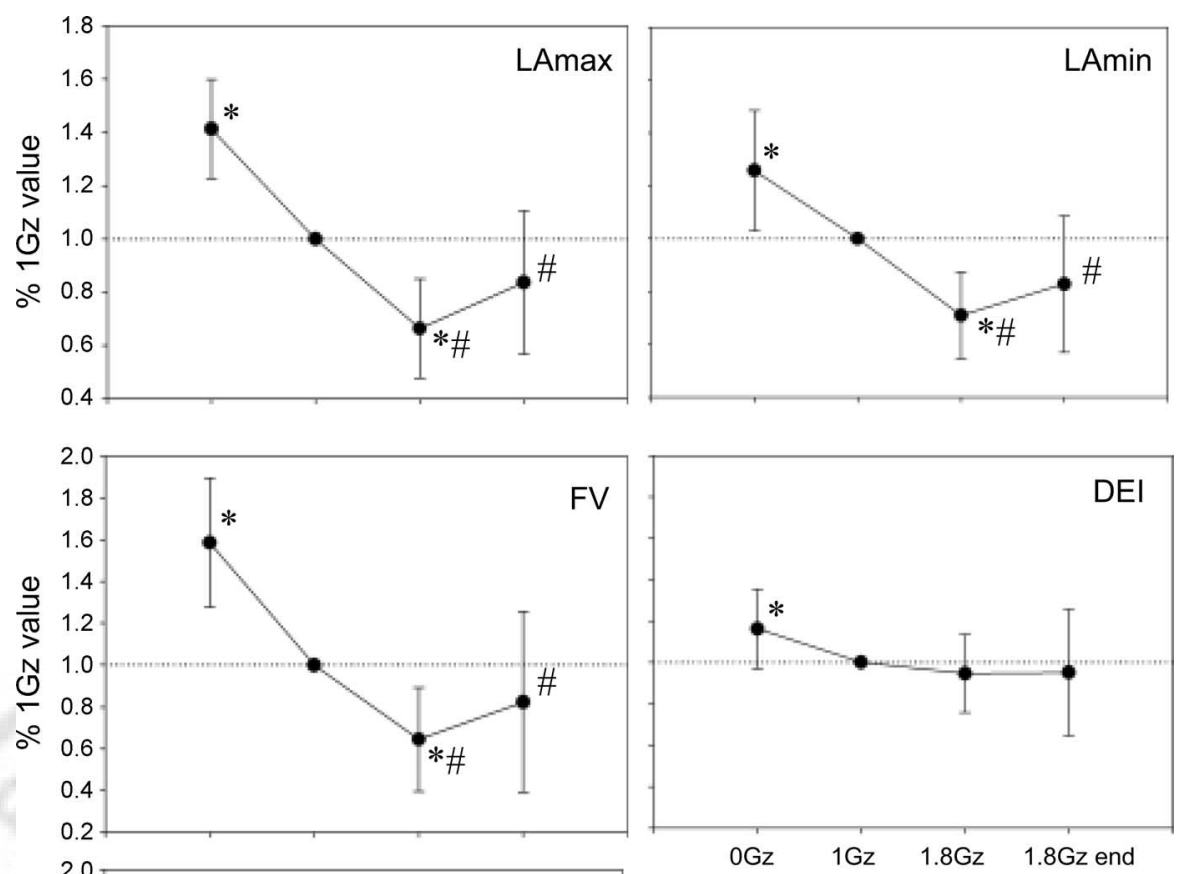

increased by 41 and $26 \%$, respectively, during $0 \mathrm{G}_{\mathrm{z}}$. As a consequence, $\mathrm{FVs}$ were reduced by $36 \%$ and increased by $59 \%$ at $1.8 \mathrm{G}_{\mathrm{z}}$ and $0 \mathrm{G}_{\mathrm{z}}$, respectively. Both DEI and EI increased during $0 \mathrm{G}_{\mathrm{z}}$ by 12 and $31 \%$, respectively (Fig. 7). LA D1 and D2 diameters at ES were increased by 28 and $18 \%$ at $0 \mathrm{G}_{\mathrm{z}}$, while at ED only D2 was found augmented by $25 \%$ compared with $1 \mathrm{G}_{\mathrm{z}}$ (Table 2).

With the activation of the LBNP countermeasure during 0 $\mathrm{G}_{\mathrm{z}}, \mathrm{LV}$ and LA volumes were quantified in 10 subjects. All LV and LA parameters trended toward $1 \mathrm{G}_{\mathrm{z}}$ values (Fig. 8), resulting in an attenuation of the changes noted at $0 \mathrm{G}_{\mathrm{z}}$ without LBNP. In particular, EDV and PFR were found reduced and restored to $1 \mathrm{G}_{\mathrm{z}}$ values. Also, $\mathrm{LA}_{\max }, \mathrm{FV}$, and DEI were reduced and not different from their values at $1 \mathrm{G}_{\mathrm{z}}$.

Table 2. Left atrial diameters computed in 14 normal subjects at $1 G_{z}$ and during $0 G_{z}$

\begin{tabular}{lcl}
\hline \hline & Phase I $\left(1 \mathrm{G}_{\mathrm{z}}\right)$ & Phase III $\left(0 \mathrm{G}_{\mathrm{z}}\right)$ \\
\hline $\mathrm{LA}_{\max } \mathrm{D} 1, \mathrm{~mm}$ & $26 \pm 5$ & $33 \pm 6^{*}(28 \%)$ \\
$\mathrm{LA}_{\max } \mathrm{D} 2, \mathrm{~mm}$ & $42 \pm 7$ & $49 \pm 8^{*}(22 \%)$ \\
$\mathrm{LA}_{\min } \mathrm{D} 1, \mathrm{~mm}$ & $18 \pm 4$ & $21 \pm 9(32 \%)$ \\
$\mathrm{LA}_{\min } \mathrm{D} 2, \mathrm{~mm}$ & $32 \pm 8$ & $39 \pm 9 *(25 \%)$ \\
\hline
\end{tabular}

Values are means $\pm \mathrm{SD}$. In parentheses, the mean percentage of increase in respect of $1 \mathrm{G}_{\mathrm{z}}$ value is reported. D1, medial-lateral dimension; D2, anteroposterior dimension. ${ }^{*} P<0.05$ vs. $1 \mathrm{G}_{\mathrm{z}}$.

\section{DISCUSSION}

This study is the first to provide 3DE data sets from complete cardiac cycles in weightlessness, allowing for the calculation of LV and LA volumes and performance data.

Cardiac ultrasound has been the only medical imaging modality used in space to evaluate cardiovascular function. However, its use for scientific purposes during spaceflights has been limited due to operational constraints and technical factors (34). Despite these limitations, 2DE has been used to measure changes in cardiac size and function during weightlessness (3, $5,37)$ and to assess the time course of postflight recovery $(2$, $6,10,25,35)$.

Parabolic flights are the only way to reproduce in humans the weightlessness (or free-falling) state that characterizes spaceflights, thus representing a unique experimental condition to study reversible and repeatable acute nonpharmacologically induced variations in venous return in the same subject. We demonstrated the feasibility of acquiring 3D data sets suitable for analysis for each gravity phase of the parabola, despite the relatively short period of time available for image acquisition. The methodology used in this study allowed us to overcome many of the limitations of 2DE imaging. In particular, the availability of a 3D pyramidal data set allowed offline selection of the anatomically correct LV long axis, from which the equi-angled long-axis cut-planes were obtained for endocardial 

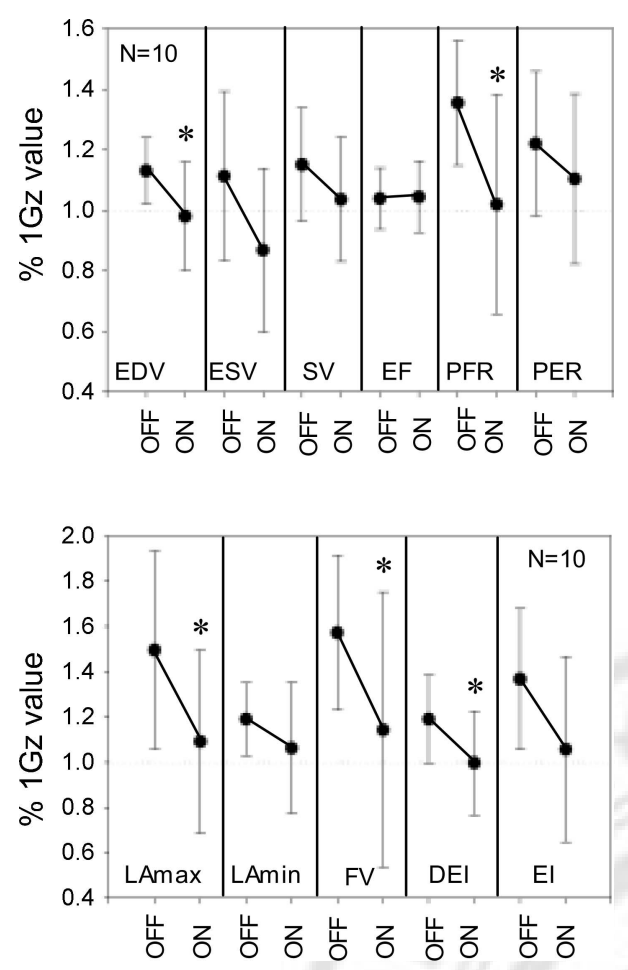

Fig. 8. Average \pm SD of LV (top) and LA (bottom) parameters measured in 10 subjects during the $0 \mathrm{G}_{\mathrm{z}}$ phase of the parabola without $(\mathrm{OFF})$ and with $(\mathrm{ON})$ LBNP at $-50 \mathrm{mmHg}$ activated. $* P<0.05$.

contour detection. This minimized LV apical foreshortening, thus preventing the underestimation of LV volumes. Also, the frame-by-frame analysis throughout the cardiac cycle allowed computation of LV volume vs. time curves, from which clinical parameters, such as PFR and PEF, were derived. From the same data sets, we also measured the effects of $0 \mathrm{G}_{\mathrm{z}}$ on LA volumes, to obtain new insights into the physiology of this chamber at $0 \mathrm{G}_{\mathrm{z}}$.

In contrast to other studies $(27,42,48)$, imaging the subjects in the standing position allowed us both to maximize the effects of abrupt gravitational fluid shift on LV and LA volumes and to study, for the first time during parabolic flight, the effects induced by LBNP.

Our results demonstrate that, when a subject experiences a higher gravitational stress (phase II, $1.8 \mathrm{G}_{\mathrm{z}}$ ), both LV and LA volumes become smaller compared with $1 \mathrm{G}_{\mathrm{z}}$ values, due to a decrease in venous return, resulting in a reduction of SV and LA FV. Interestingly, during the second $1.8 \mathrm{G}_{\mathrm{z}}$ phase (phase IV), these parameters were also significantly reduced compared with $0 \mathrm{G}_{\mathrm{z}}$ but not different from $1 \mathrm{G}_{\mathrm{z}}$ values. As the left heart is more dilated at the beginning of phase IV compared with the onset of phase II, the $1.8 \mathrm{G}_{\mathrm{z}}$ induced reduction in $\mathrm{LV}$ and LA volumes appears to be independent from the gravity gradient $\left(+0.8 \mathrm{G}_{\mathrm{z}}\right.$ in phase II and $+1.8 \mathrm{G}_{\mathrm{z}}$ in phase IV) and more directly related to the magnitude of the preexisting $\mathrm{LV}$ and LA volumes when entering the $1.8 \mathrm{G}_{\mathrm{z}}$ phase.

In contrast, when the subject is in $0 \mathrm{G}_{\mathrm{z}}$, both ED and ES LV volumes augment by $\sim 20 \%$ compared with $1 \mathrm{G}_{\mathrm{z}}$ values, resulting in an increase in $\mathrm{SV}$, while $\mathrm{EF}$ remains unchanged. These LV volume changes have been previously shown to be due to the increase in central blood volume that occurs in weightlessness. The increase in cardiac volumes occurs, despite a decrease in central venous pressure (48), potentially due to a reduction in intrathoracic pressure and/or to the loss of compressive forces that occurs throughout the body in weightlessness.

In a previous study, where we measured LV area changes from $2 \mathrm{DE}$ in the apical four-chamber view using a similar experimental setting, we reported an increase in LV area at 0 $\mathrm{G}_{\mathrm{z}}$ of only $12 \%$ (17). Compared with the current results, the underestimation found with $2 \mathrm{DE}$ was probably due to apical foreshortening, caused by the difficulties in continuously acquiring the correct anatomical $2 \mathrm{D}$ plane during the parabola. Our observations on LV volume changes at $0 \mathrm{G}_{\mathrm{z}}$ induced by parabolic flight closely resemble the short-term effects of $0 \mathrm{G}_{\mathrm{z}}$ on LV dimensions occurring in astronauts during the initial 2-3 days of spaceflight (9). These data reinforce the notion that parabolic flight represents a unique setting to study the shortterm effects of weightlessness on Earth.

The observed increase in the rapid $\mathrm{LV}$ filling during $0 \mathrm{G}_{\mathrm{z}}$ is in agreement with our laboratory's previous observation that a significant increase in the peak mitral $\mathrm{E}$ wave occurs in standing subjects during $0 \mathrm{G}_{\mathrm{z}}$ (12) due to increased LV preload. The observed increase in PER could be explained by both increased LV ED pressure caused by the EDV augmentation, and by probable afterload reduction due to decreased blood pressure with $0 \mathrm{G}_{\mathrm{z}}(7,42)$.

With regard to the LA, we found that, at $0 \mathrm{G}_{\mathrm{z}}$, both the ED and ES LA volumes increased considerably compared with 1 $\mathrm{G}_{\mathrm{z}}$ values, resulting in an increase in both the LA reservoir function (i.e., FV and EI) and in the overall DEI. Previously, Videbaek and Norsk (48) studied the ES LA diameter by M-mode from the parasternal long-axis view in subjects in the supine position during parabolic flight, reporting a $15 \%$ increase at $0 \mathrm{G}_{\mathrm{z}}$ compared with $1 \mathrm{G}_{\mathrm{z}}$. The measurement of only a single diameter of the LA represented a limitation of that study, because it assumed that a consistent relationship is maintained between the anteroposterior and all other LA dimensions as the atrium enlarges, which is often not the case $(32,33)$. Our results obtained with RT3DE measured the true atrial volume and demonstrated that the magnitude of LA distension at $0 \mathrm{G}_{\mathrm{z}}$ appears to be larger (approximately doubled) than previously reported. Moreover, changes in LA D1 and D2 diameters at $0 \mathrm{G}_{\mathrm{z}}$ evidenced a similar increase of $\sim 7 \mathrm{~mm}$ in D1 and D2 at ES, demonstrating a symmetric distension of the LA following an abrupt increase in venous return.

These findings could be considered for the formulation of new qualification criteria for commercial space travel. Since the increase in venous return induced by $0 \mathrm{G}_{\mathrm{z}}$ generates a considerable increase in LA and LV volumes, a compliant LV is required to avoid any abrupt increase in filling pressures. Noninvasive maneuvers resulting in significant preload augmentation (i.e., $-40^{\circ}$ head-down tilt) could be used in the future to ensure LV compliance. In fact, we can hypothesize that, when entering weightlessness, individuals with compromised LV compliance could develop pulmonary edema, resulting in different clinical scenarios, which could range from a reduction of in-flight performance to a life-threatening condition.

LBNP has been used as a test of orthostatic tolerance both on Earth and during long-term spaceflights, and as an in-flight countermeasure prior to reentry, associated with fluid intake, to 
prevent postflight orthostatic intolerance. Although previous studies investigated the effects of LBNP on LV dimensions in various experimental conditions using $2 \mathrm{DE}(4,28,39,45,46)$, this is the first time that LBNP has been studied during parabolic flight, to assess in a weightlessness environment its counterbalancing effects on LV and LA volumes in a normal heart. In ground experiments, performed in subjects in the supine position, a reduction in LV volumes and SV with LBNP at different pressures (from -10 to $-40 \mathrm{mmHg}$ ) have been previously reported using M-mode echocardiography $(28,39)$. Our results obtained in subjects in standing position during 0 $\mathrm{G}_{\mathrm{z}}$ showed that LBNP at $-50 \mathrm{mmHg}$ was able to restore $\mathrm{LV}$ and LA dimensions to $1 \mathrm{G}_{\mathrm{z}}$ values, in particular LV EDV, $\mathrm{LA}_{\max }$, and LA FV. Since LBNP is known to increase the pooling of blood in the lower body, leading to decreases in both central blood volume and cardiac filling pressures $(1,14$, 40,47 ), and since $0 \mathrm{G}_{\mathrm{z}}$ has been shown to increase central blood volume and atrial distension (48), the combined effect of $0 \mathrm{G}_{\mathrm{z}}$ and LBNP appears to counterbalance each other, resulting in minimal change in central blood volume.

This study had several limitations. First, 3DE using a fullmatrix array transducer has been previously described as being a "real-time" technique. However, data were acquired in the full volume mode, which is a "near" real-time technique that requires temporal registration of a number of subsegments acquired from consecutive beats. Accordingly, it was not possible to acquire data sets representative of consecutive cardiac cycles along the whole parabola, but only one data set for each gravity phase. However, after the short transient when entering in a new gravity phase, the LV and LA volumes can be considered stabilized and representative of the corresponding parabolic phase. Furthermore, in the interpretation of the results, when the effects of $1 \mathrm{G}_{\mathrm{z}}$ are compared with those of weightlessness, it is important to consider the effects of the 1.8 $\mathrm{G}_{\mathrm{z}}$ phase occurring in between.

The semiautomated segmentation procedure requires the manual initialization of the endocardial borders in multiple, evenly rotated long-axis views, which is a time-consuming and subjective procedure. Nevertheless, this technique, applied to the LV, was found to be highly reproducible and accurate (30). As no standard analysis methods for LA volume quantification from RT3DE data exist, our measurements of absolute LA dimensions could be affected by biases or inaccuracies. However, as these errors should be of the same magnitude for each gravity phase, and since results were normalized in each subject for the corresponding $1 \mathrm{G}_{\mathrm{z}}$ values, the resulting change in LA volumes should not be affected by the method of analysis.

In conclusion, the result of this study indicates that RT3DE imaging during parabolic flight is feasible and provides the basis for accurate quantification of LV volume changes with gravity, thus providing pyramidal data sets from which correct non-foreshortened apical views can be obtained. Moreover, also, LA volume changes during weightlessness can be quantified by RT3DE. In $0 \mathrm{G}_{\mathrm{z}}$, we reported an increase of both $\mathrm{LV}$ and LA volumes, due to changes in venous return, which was counteracted by LBNP.

\section{ACKNOWLEDGMENTS}

We acknowledge the dedicated collaboration of the crew of Centre National d'Etudes Spatiales (CNES) Airbus A300 ZERO-G operated by Novespace.
The invaluable support of Steve Anderson, Heinrich Beckermann, Stephane Husson, and Arnoud Perrin from Philips Medical Systems has been greatly appreciated.

\section{GRANTS}

We acknowledge the support from CNES and the European Space Agency (ESA). P. Vaïda was the recipient of Grant 02/CNES/4800000039 from CNES. Philips Medical Systems provided an equipment grant as well as a grant-in-aid to support this project.

\section{REFERENCES}

1. Ahmad M, Blomqvist CG, Mullins CB, and Willerson JT. Left ventricular function during lower body negative-pressure. Aviat Space Environ Med 48: 512-515, 1977.

2. Arbeille P, AchaiBou F, Fomina G, Pottier JM, and Porcher M. Regional blood flow in microgravity: adaptation and deconditioning. Med Sci Sports Exerc 28: S70-S79, 1996.

3. Arbeille P, Fomina G, Roumy J, Alferova I, Tobal N, and Herault $\mathbf{S}$. Adaptation of the left heart, cerebral and femoral arteries, and jugular and femoral veins during short- and long-term head-down tilt and space flights. Eur J Appl Physiol 86: 157-168, 2001.

4. Arbeille P, Lebouard D, Massabuau M, Pottier JM, Patat F, Pourcelot L, and Guell A. Effect on the cardiac function of repeated LBNP during a 1-month head down tilt. Acta Astronaut 25: 415-418, 1991.

5. Atkov O, Bednenko VS, and Fomina GA. Ultrasound techniques in space medicine. Aviat Space Environ Med 58: A69-A73, 1987.

6. Blomqvist GC. Regulation of the systemic circulation at microgravity and during readaptation to 1G. Med Sci Sports Exerc 28: S9-S13, 1996.

7. Buckey JC. Central venous pressure. In: Gravity and the Lung: Lessons from Microgravity, edited by Prisk GK, West JB, and Paiva M. New York: Dekker, 2001.

8. Buckey JC, Gaffney FA, Lane LD, Levine BD, and Blomqvist CG. Central venous pressure in space. N Engl J Med 328: 1853-1854, 1993.

9. Bungo MW, Charles JB, Riddle J, Roesch J, Wolf DA, and Seddon MR. Human echocardiographic examinations during spaceflight. Aviat Space Environ Med 57: 494, 1986.

10. Bungo MW, Goldwater DJ, Popp RL, and Sandler H. Echocardiographic evaluation of Space-Shuttle crewmembers. J Appl Physiol 62: $278-283,1987$.

11. Bungo MW and Johnson PC. Cardiovascular examinations and observations of deconditioning during the Space-Shuttle orbital flight test program. Aviat Space Environ Med 54: 1001-1004, 1983.

12. Caiani EG, Asquer G, Turiel M, Bailliart O, Cholley B, Capderou A, and Vaida P. Changes in Doppler mitral inflow patterns during parabolic flight. J Gravit Physiol 11: P93-P94, 2004.

13. Caiani EG, Corsi C, Zamorano J, Sugeng L, MacEneaney P, Weinert L, Battani R, Gutierrez JL, Koch R, Perez-Isla L, Mor-Avi V, and Lang RM. Improved semi-automated quantification of left ventricular volumes and ejection fraction using three-dimensional echocardiography with a full-matrix array transducer: comparison with MRI. J Am Soc Echocardiogr 18: 779-788, 2005.

14. Chang CM, Cassuto Y, Pendergast DR, and Farhi LE. Cardiorespiratory response to lower-body negative-pressure. Aviat Space Environ Med 65: 615-620, 1994.

15. Charles JB and Bungo MW. Cardiovascular physiology in space-flight. Exp Gerontol 26: 163-168, 1991.

16. Charles JB and Lathers CM. Cardiovascular adaptation to space-flight. J Clin Pharmacol 31: 1010-1023, 1991.

17. Corsi C, Lamberti C, Cerutti S, Laulom JP, Bailliart O, Cholley B, Capderou A, Vaida P, and Caiani EG. Level-set based technique for the quantification of left ventricular size and function in 2-D echocardiography during parabolic flights. Med Biol Eng Comput 42: 610-617, 2004.

18. Corsi C, Lang RM, Veronesi F, Weinert L, Caiani EG, MacEneaney P, Lamberti C, and Mor-Avi V. Volumetric quantification of global and regional left ventricular function from real-time three-dimensional echocardiographic images. Circulation 112: 1161-1170, 2005.

19. Folland ED, Parisi AF, Moynihan PF, Jones DR, Feldman CL, and Tow DE. Assessment of left ventricular ejection fraction and volumes by real-time, 2-dimensional echocardiography. Comparison of cineangiographic and radionuclide techniques. Circulation 60: 760-766, 1979.

20. Fritsch JM, Charles JB, Bennett BS, Jones MM, and Eckberg DL. Short-duration spaceflight impairs human carotid baroreceptor-cardiac reflex responses. J Appl Physiol 73: 664-671, 1992. 
21. Fritschyelle JM, Charles JB, Jones MM, Beightol LA, and Eckberg DL. Spaceflight alters autonomic regulation of arterial pressure in humans. J Appl Physiol 77: 1776-1783, 1994.

22. Guell A and Braak L. Cardiovascular deconditioning syndrome during space flight. Ann Cardiol Angeiol (Paris) 38: 499-502, 1989.

23. Hargens AR and Watenpaugh DE. Cardiovascular adaptation to spaceflight. Med Sci Sports Exerc 28: 977-982, 1996.

24. Hargens AR, Whalen RT, Watenpaugh DE, Schwandt DF, and Krock LP. Lower-body negative-pressure to provide load bearing in space. Aviat Space Environ Med 62: 934-937, 1991.

25. Henry WL, Epstein SE, Griffith JM, Goldstein RE, and Redwood DR. Effect of prolonged space flight on cardiac function and dimensions. In: Biomedical Results from Skylab, edited by Johnston RS and Dietlein LF. Washington, DC: NASA, 1977, p. 366-371.

26. Jenkins C, Bricknell K, Hanekom L, and Marwick TH. Reproducibility and accuracy of echocardiographic measurements of left ventricular parameters using real-time three-dimensional echocardiography. $J$ Am Coll Cardiol 44: 878-886, 2004.

27. Johns JP, Vernalis MN, Karemaker JM, and Latham RD. Doppler evaluation of cardiac filling and ejection properties in humans during parabolic flight. J Appl Physiol 76: 2621-2626, 1994.

28. Kitano A, Shoemaker JK, Ichinose M, Wada H, and Nishiyasu T. Comparison of cardiovascular responses between lower body negative pressure and head-up tilt. J Appl Physiol 98: 2081-2086, 2005.

29. Kuhl HP, Franke A, Merx M, Hoffmann R, Puschmann D, and Hanrath P. Quantification of left ventricular function and mass using transesophageal three-dimensional echocardiography: validation of a method that uses long-axis cut-planes. Eur J Echocardiogr 1: 213-221, 2000.

30. Kuhl HP, Schreckenberg M, Rulands D, Katoh M, Schafer W, Schummers G, Bucker A, Hanrath P, and Franke A. High-resolution transthoracic real-time three-dimensional echocardiography-quantitation of cardiac volumes and function using semi-automatic border detection and comparison with cardiac magnetic resonance imaging. J Am Coll Cardiol 43: 2083-2090, 2004.

31. Lathers CM, Charles JB, Elton KF, Holt TA, Mucai C, Bennet BS, and Bungo MW. Acute hemodynamic responses to weightlessness in humans. J Clin Pharmacol 29: 615-627, 1989.

32. Lester SJ, Ryan EW, Schiller NB, and Foster E. Best method in clinical practice and in research studies to determine left atrial size. Am J Cardiol 84: 829-832, 1999.

33. Loperfido F, Pennestri F, Digaetano A, Scabbia E, Santarelli P, Mongiardo R, Schiavoni G, Coppola E, and Manzoli U. Assessment of left atrial dimensions by cross-sectional echocardiography in patients with mitral-valve disease. Br Heart J 50: 570-578, 1983.

34. Martin DS, South DA, Garcia KM, and Arbeille P. Ultrasound in space. Ultrasound Med Biol 29: 1-12, 2003.

35. Martin DS, South DA, Wood ML, Bungo MW, and Meck JV. Comparison of echocardiographic changes after short- and long-duration spaceflight. Aviat Space Environ Med 73: 532-536, 2002.

36. Mor-Avi V, Sugeng L, Weinert L, MacEneaney P, Caiani EG, Koch R, Salgo IS, and Lang RM. Fast measurement of left ventricular mass with real-time three-dimensional echocardiography. Comparison with magnetic resonance imaging. Circulation 110: 1814-1818, 2004.
37. Mulvagh SL, Charles JB, Riddle JM, Rehbein TL, and Bungo MW. Echocardiographic evaluation of the cardiovascular effects of short-duration spaceflight. J Clin Pharmacol 31: 1024-1026, 1991.

38. Murthy G, Watenpaugh DE, Ballard RE, and Hargens AR. Exercise against lower-body negative-pressure as a countermeasure for cardiovascular and musculoskeletal deconditioning. Acta Astronaut 33: 89-96, 1994.

39. Pela G, Regolisti G, Coghi P, Cabassi A, Basile A, Cavatorta A, Manca C, and Borghetti A. Effects of the reduction of preload on left and right ventricular myocardial velocities analyzed by Doppler tissue echocardiography in healthy subjects. Eur J Echocardiogr 5: 262-271, 2004.

40. Poliner LR, Dehmer GJ, Lewis SE, Parkey RW, Blomqvist CG, and Willerson JT. Left ventricular performance in normal subjects-a comparison of the responses to exercise in the upright and supine positions. Circulation 62: 528-534, 1980.

41. Prisk GK, Guy HJB, Elliott AR, Deutschman RA, and West JB. Pulmonary diffusing capacity, capillary blood-volume, and cardiac-output during sustained microgravity. J Appl Physiol 75: 15-26, 1993.

42. Pump B, Vldebaek R, Gabrielsen A, and Norsk P. Arterial pressure in humans during weightlessness induced by parabolic flights. J Appl Physiol 87: 928-932, 1999.

43. Schnittger I, Fitzgerald PJ, Daughters GT, Ingels NB, Kantrowitz NE, Schwarzkopf A, Mead CW, and Popp RL. Limitations of comparing left ventricular volumes by 2 dimensional echocardiography, myocardial markers and cineangiography. Am J Cardiol 50: 512-519, 1982.

44. Spencer KT, Mor-Avi V, Gorcsan J, DeMaria AN, Kimball TR, Monaghan MJ, Perez JE, Weinert L, Bednarz J, Edelman K, Kwan OL, Glascock B, Hancock J, Baumann C, and Lang RM. Effects of aging on left atrial reservoir, conduit, and booster pump function: a multi-institution acoustic quantification study. Heart 85: 272-277, 2001.

45. Takenaka K, Suzuki Y, Kawakubo K, Haruna Y, Yanagibori R, Iwamoto S, Igarashi $\mathbf{M}$, Watanabe F, Omata M, Bonde-Petersen F, and Gunji A. Cardiovascular response to lower body negative pressure before and after 20 days horizontal bed rest. J Gravit Physiol 4: S58-S61, 1997.

46. Takenaka K, Suzuki Y, Uno K, Sato M, Komuro T, Haruna Y, Kobayashi H, Kawakubo K, Sonoda M, Asakawa M, Nakahara K, and Gunji A. Effects of rapid saline infusion on orthostatic intolerance and autonomic tone after 20 days bed rest. Am J Cardiol 89: 557-561, 2002.

47. Tripathi A, Mack G, and Nadel ER. Peripheral vascular reflexes elicited during lower body negative-pressure. Aviat Space Environ Med 60: 1187-1193, 1989.

48. Videbaek $\mathbf{R}$ and Norsk $\mathbf{P}$. Atrial distension in humans during microgravity induced by parabolic flights. J Appl Physiol 83: 1862-1866, 1997.

49. Wyatt HL, Meerbaum S, Heng MK, Gueret P, and Corday E. Crosssectional echocardiography. 3. Analysis of mathematic models for quantifying volume of symmetric and asymmetric left ventricles. Am Heart $J$ 100: 821-828, 1980.

50. Zoghbi WA, Buckey JC, Massey MA, and Blomqvist CG. Determination of left-ventricular volumes with use of a new nongeometric echocardiographic method-clinical validation and potential application. J Am Coll Cardiol 15: 610-617, 1990. 


\section{AUTHOR QUERIES}

\section{AUTHOR PLEASE ANSWER ALL QUERIES}

AQ6 - Please verify accuracy of your e-mail address in the address for correspondence, or delete e-mail address if you do not want it included. (note: this material is listed as a footnote at bottom of left column of text, on the first page)

AQ1- Please read proof, answer queries, and make corrections in margins. Return galley proof and query sheet by overnight/express carrier within $48 \mathrm{~h}$ to The American Physiological Society, Journal of Applied Physiology, 9650 Rockville Pike, Bethesda, MD 20814-3991 USA. Please make a copy of the proofs, with your corrections, for your records. Thank you.

AQ2- Please define "CCML" in the list of affiliations.

AQ3 - Words and phrases from the title do not need to be reiterated in the key word list, so redundancies have been deleted from this list. You may add up to 3 more terms, if you wish.

AQ4- In Table 1 legend, you defined \# as $P<0.05$ vs. 0 Gz. However, this symbol did not appear in the table. Therefore, I deleted it the legend. If the symbol should be in the table, please indicate where it should go.

AQ5- Is ref. 9 an abstract or a 1-page article?

AQ7- Ed: Some figs. ahead of cites to avoid ref. page. 